\title{
The role of a thermally sprayed CuNiln underlayer in the durability of a dry-film lubricant system in fretting - a phenomenological
}

modela microstructural study

K. Barman ${ }^{1}$, P.H. Shipway ${ }^{1}$, K.T. Voisey*1, G. Pattinson ${ }^{2}$

1. Faculty of Engineering, The University of Nottingham, United Kingdom.

2. Rolls-Royce plc, Derby, United Kingdom.

\section{Abstract}

Dry film lubricant coatings (DFL) are employed to reduce friction and damage in highly loaded contacts. Metallic underlayers, e.g. CuNiln, can be beneficial however, there is no detailed explanation of the mechanism. This work investigates the effect of CuNiln on fretting of a MoS -based DFL in a cylinder-on-flat contact with a fretting amplitude of $300 \mu \mathrm{m}$. Two test types were run: 1 . DFL without CuNiln; 2. DFL on the cylindrical sample and DFL with CuNiln underlayer on the flat sample. The CuNiln increased the system's durability. A phenomenological model highlighting the important low friction and highly wear resistant interfacial material is developed. The increased durability is ascribed to the high roughness of the CuNiln onto which the DFL was deposited.

Keywords: fretting; molybdenum disulphide; molybdenum disulphide; CuNiln;

* Corresponding author: K.T. Voisey

\section{Introduction}

The fan blade/ disk dovetail in an aero-engine system is a highly loaded contact subject to mechanical vibration. Relative motion at the contact can lead fretting wear and fretting fatigue [1-5]-. In this application both components in the contact are typically made from titanium alloys and, due to the poor tribological behaviour (high coefficient of friction and high rate of wear) of self-mated titanium alloys, a number of surface engineering approaches to combat fretting damage have been developed. of low-friction coatings having been developed to combat fretting damage [6-8]. These include processes such as low plasticity burnishing [6], surface rolling [7] and various peening techniques [811], all of which induce a compressive mean stress to arrest crack propagation. Low-friction coatings have also been developed to combat fretting damage, i.e. to stop fretting crack initiation [12-14]. Such anti-friction coatings are intended to extend lifetimes, resulting in less frequent engine maintenance and associated downtime. Lower rates of wear of the lubricant film itself are associated with longer lifetimes. As low friction leads to a decrease in frictional energy dissipation and thus to reduced damage induced by wear, the desire for low friction and long lifetimes are frequently complimentary.

The most commonly employed systems utilise a duplex surface engineering solution; onto the titanium alloy, a metallic layer (typically 100 - $150 \mu \mathrm{m}$ thick) of a copper-nickel-indium (CuNiln) alloy is plasma-sprayed. On top of that, a solid-lubricant doped polymer-based paint is deposited (typically 
$30-50 \mu \mathrm{m}$ thick); the solid lubricant most commonly employed is molybdenum disulphide ( $\left.\mathrm{MoS}_{2}\right)$ [15]. In the work of Kim and Korsunsky [16], a titanium alloy was plasma-sprayed with a CuNiln layer which then had an epoxy-bonded $\mathrm{MoS}_{2}$ layer deposited on top of that; this was fretted against a titanium alloy which had the $\mathrm{MoS}_{2}$ layer deposited directly onto it. It was suggested that such a configuration most closely resembles that found in aerospace components (the CuNiln is not applied to one of the components due to access issues).

Fridrici et al. [17] examined the fretting behaviour of a system with a DFL (dry film lubricant) which was deposited onto a plasma sprayed CuNiln coating. The CuNiln was reported to have a Vickers Hardness of $170 \mathrm{kgf} \mathrm{mm}^{-2}$ and an as-sprayed roughness ( $\left.\mathrm{Ra}\right)$ of $8 \mu \mathrm{m}$. It was argued that this roughness promoted retention of the DFL layer. In addition, it was noted that the Young's modulus of the CuNiln was around a half of that of the titanium alloy substrate, and as such, the addition of the CuNiln reduced the contact stiffness and resulted in a larger contact area and a reduction in contact stress. Moreover, Sabeya et al. [18] noted that the function of the CuNiln coating is to accommodate plastic deformation which thus limits cracking in the substrate (component) material. More explicitly, Fouvry et al. [19] argued that "a major part" of the strain imposed through the interface of a fretting contact is "accommodated by plastic deformations through the bronze coating". It has also been noted [19] that the lifetime of such a system may not be related to the removal of the DFL to reveal the underlying metals, but instead it is associated with a total oxidation of the $\mathrm{MoS}_{2}$ phase in the interfacial material. However, it has also been noted that the epoxy-based DFL is rapidly removed from such a system, and accordingly the fretting behaviour of titanium alloy against CuNiln -coated titanium alloys has been the subject of investigation $[2,15]$. It was noted that, although the CuNiln itself can be used "to act as a sacrificial barrier that protects both the blade and disk by preventing the Ti6Al4V surfaces from coming in contact with each other"[20], significant damage can be caused to the titanium alloy by fretting against the plasma-sprayed coating [21].

Recent work by the current authors [22] has explored the fretting behaviour of DFL-coated titanium alloys (with no CuNiln underlayer). This work showed that-and has shown that the evolution of the coating takes place in three stages, as described by the energy coefficient of friction (ECOF). The ECoF is based on the dissipated energy per cycle [23]. The key advantage of the ECoF is that, unlike the coefficient of friction, it is not strongly affected by affects at the end of the traverse such as build-up of ploughed material.coefficient of friction. An example of the ECoF evolution with number of cycles is presented in Figure 1, along with a categorization into three stages as follows: in Stage I, the coefficient of friction at first rises, and then slowly falls or remains approximately constant. At the start of Stage II, the coefficient of friction falls (generally quite rapidly) until a minimum point is reached; the ECoF then rises slowly and steadily from this minimum point until it starts to exhibit short term instability; this is defined as the end of Stage II. In Stage III, the coefficient of friction continues to exhibit short term instability (periods of high friction) but also continues to rise until the test is terminated. The total number of cycles in each stage is thus defined as $N_{1}, N_{\| I}$ and $N_{\| 1 I}$, where the subscript refers to the appropriate stage. It was argued that the practical lifetime of the system includes Stages I and II, but that in Stage III, the behaviour is more stochastic and is moving towards system failure (as characterized by significant loss of material and by high coefficient of friction). Stage I was identified as the region where the DFL itself was being worn, with the end of Stage I representing the point of involvement of the metallic substrates in the contact. The wear of the substrate in Stage II was, however, minimal, with the development of a low friction coating across the surface (which limited direct metal-metal contact); this low friction coating was associated with the incorporation of species from the DFL. The end of Stage II is thus defined as the point at which this low friction layer is exhausted, and that substrate metal-metal contact (with its associated high friction) begins to dominate the interaction between the surfaces. 
The current work seeks to understand the role of the CuNiln underlayer in the fretting lifetime of an epoxy-bonded $\mathrm{MoS}_{2}$-based DFL system. Both specimens in the fretting pair were titanium alloy (Ti6Al4V). In the first case, one of the specimens had a CuNiln underlayer applied (to replicate typical current practice [16]) before both surfaces were then coated with the epoxy-bonded $\mathrm{MoS}_{2} \mathrm{DFL}$; in the second case, both titanium alloy surfaces were both coated with the epoxy-bonded MoS DFL (no CuNiln underlayer was applied). The evolution of the coefficient of friction throughout the fretting tests was monitored for both coating architectures in both full tests and interrupted tests, along with detailed characterization of the ensuing wear scars.

\section{Experimental Methods}

The same crossed cylinder-on-flat configuration used in the authors' earlier work [22] was used for the fretting wear tests, with the cylindrical samples having a radius of $15 \mathrm{~mm}$. These were conducted in two configurations; in the first configuration, both the flat and cylindrical specimens making up the fretting couple were grit blasted with aluminum oxide grit (Airblast, UK; grade NK36) with a grit size $0.50-0.59 \mathrm{~mm}$, yielding surfaces with a roughness $(\mathrm{Ra})$ of around $2.1 \mu \mathrm{m}$. Immediately following grit blasting, a commercially available polymer-based DFL paint (PL237 R2, Indestructible Paints, Birmingham, UK in which the primary solid lubricant phase in the DFL is $\mathrm{MoS}_{2}$ ) was applied using a spray deposition technique. Hereafter, the PL237 paint will be referred to as the DFL, and the like-onlike fretting pair will be referred to as the DFL-Ti6AI4V contact architecture.

In the second configuration, the flat specimens had a thermally-sprayed CuNiln metallic underlayer applied by an external contractor, using Metco 58 feedstock powder (supplied by Oerlikon Metco). This gas atomised feedstock powder has a composition of Cu 59 wt\%, Ni 36 wt\% and In 5 wt\% and a nominal size distribution of $-75+45 \mu \mathrm{m}$, indicating that $90 \%$ of the particles lie in this size range. The CuNiln underlayer had an approximate thickness of $150 \mu \mathrm{m}$ and a roughness $(\mathrm{Ra})$ of $9.0 \mu \mathrm{m}$. The same DFL was applied directly to the as-received surface of the thermally-sprayed samples (i.e. no further grit blast was applied). In this test configuration, the cylindrical specimens were prepared as before (i.e. without the CuNiln underlayer). This pair architecture (with different specimen types) is referred to as the DFL-CuNiln-Ti6AI4V contact architecture.

Micro-hardness measurements of the Ti6Al4V substrate and the CuNiln metallic layer were obtained from resin mounted cross-sections. A $200 \mathrm{~g}$ load was used, the diagonals of the indentations produced were measured and the $H V$ determined by the ratio of $F / A$, where $F$ is the force applied to the diamond in kilograms-force and $A$ is the surface area of the resulting indentation in square millimetres. In each case five separate indentations were carried out and the values reported are the average of the results obtained.

In all cases, to achieve the target DFL paint thickness of $50 \mu \mathrm{m}$, several painting passes were used, with approximately ten minutes allowed between each successive painting pass. Flat and cylindrical specimens were painted in batches together. The paints on the coated specimens were cured in an air-circulatory oven. Samples were placed in the oven initially at $100^{\circ} \mathrm{C}$; the oven temperature was then immediately increased by $2^{\circ} \mathrm{C} \mathrm{min}-1$ to $195 \pm 1{ }^{\circ} \mathrm{C}$ where it was held for $2 \mathrm{~h}$. The oven was then switched off and the cured samples remained in the oven whilst they cooled to room temperature. A PosiTector 6000 eddy current gauge (DeFelsko Corporation, USA) was used to measure the cured coating thickness, $t$, with a precision of $\pm 5 \mu \mathrm{m}$. Taking into account this uncertainty, in each case examined, the DFL thickness was the same on both the flat and cylindrical specimens. 
The conditions for fretting used in this study are summarized in Table 1 and were selected to be representative of aerospace components where DFLs of this type are employed [16]. The results are presented using the energy coefficient of friction (ECoF), as detailed in our previous work [22], to describe the evolution of the coefficient of friction.

During the fretting tests, the tractional force and applied displacement were recorded at a rate of 200 measurements per fretting cycle, and were plotted to form fretting loops. The schematic diagram of a typical fretting loop presented in Figure 2 shows a loop typical of those observed in this work where there were significant variations in the tractional force across the period of slip within each loop. The coefficient of friction (COF) in each cycle was defined as follows:

$\operatorname{CoF}=\frac{Q^{*}}{P}$ Equation [1]

where $Q^{*}$ is as defined in Figure 2. For each condition examined, tests to completion were terminated when the CoF reached a value of 0.7 (this value was chosen as it was the value observed after a low number ( 6000 ) of cycles for fretting of uncoated Ti6Al4V samples in this configuration); these are termed completed tests.

It is recognized that the definition of the CoF (using the maximum tractional force) is strongly influenced by effects at the end of the traverse (such as build-up of ploughed material); another commonly used measure is that known as the energy coefficient of friction (ECOF) [23] which is based on the dissipated energy per cycle ( $E_{d}$ - as defined in Figure 2),

$E C o F=\frac{E_{d}}{4 P \delta}$ Equation [2]

with $\delta$ being the slip amplitude (distinct from the applied displacement amplitude, $\Delta^{*}$ ); both of these parameters are illustrated in Figure 2.

Interrupted tests were conducted on selected samples from the test matrix, with the point of interruption being selected to be in region of interest, determined from the development of ECoF versus fretting cycles from the completed tests. Such tests were designed to facilitate a better understanding of the nature of the wear processes in the different stages. Also, as in our previous work [22], the in-test control system which was used to terminate tests was based upon the CoF rather than the ECoF which means that the ECoF at termination of the test was always less than 0.7.

Following testing, the geometry of the wear scars on the flat sample in each wear couple was characterized using a Taylor-Hobson Talysurf CLI 1000 contact profilometer. The central $8 \mathrm{~mm}$ region of the wear scar was scanned with 54 lines, all parallel to the sliding direction and spaced $150 \mu \mathrm{m}$ apart (see Figure 2Figure 2). The average profile of the scar was formed by taking the average of the 54 line scans, and using the material outside the scar as a reference surface. The surfaces of the wear scars were also characterized using scanning electron microscopy (Philips XL30), using both secondary electron (SE) and backscattered electron (BSE) imaging along with energy dispersive $\mathrm{X}$-ray analysis (EDX) conducted at $20 \mathrm{kV}$ and a working distance of $10 \mathrm{~mm}$. In addition, X-ray photoelectron spectroscopy (XPS) was conducted using a Kratos AXIS ULTRA with a mono-chromated AI Ka X-ray source $(1486.6 \mathrm{eV})$ operated with an emission current of $10 \mathrm{~mA}$ and an anode potential of $12 \mathrm{kV}$. A pass energy of $20 \mathrm{eV}$ was employed with a step size of $0.1 \mathrm{eV}$, with the area of analysis being defined by an aperture of $300 \times 700 \mu \mathrm{m}$. A charge neutraliser was used to prevent sample surface charging. 
The flat samples were analysed following fretting with a spacing of $0.5 \mathrm{~mm}$ between analysis positions stepping across the wear scar.

\section{Results}

Figure 3-Figure 3 shows the surfaces to which the DFL paints were applied. The roughnesses were 2.1 $\mu \mathrm{m}$ and $9.0 \mu \mathrm{m}$ for the grit-blasted Ti6Al4V surface and the CuNiln surface respectively. Figure 4 Figure 4 shows line surface profiles on the two surfaces before application of the DFL paint; both long-range and short-range differences in surface profile can be seen, with the CuNiln surface displaying a peakto-trough variation of more than $40 \mu \mathrm{m}$. The hardness of the Ti6Al4V substrate was $287 \pm 10 \mathrm{kgf} \mathrm{mm}$ 2 and that of the CuNiln interlayer was $177 \pm 20 \mathrm{kgf} \mathrm{mm}^{-2}$. Figure 65Figure 5 shows plan-view SEM images of the as-cured DFL coating deposited on the titanium alloy substrate, where it can be seen that the film is a bonded agglomerate of individual $\mathrm{MoS}_{2}$ particles; the appearance of this surface was very similar to when the DFL coating was applied on top of the plasma-sprayed CuNiln.

Figure 6-Figure 6 shows the development of ECoF for both interrupted and completed tests for the two contact architectures. In both Figure 6 a \& c, superposition of interrupted and completed tests illustrates the high level of run-to-run reproducibility in fretting results, a feature that was also seen in our earlier work [24]

; in each-caseFor both contact architectures, the corresponding depth profile across the wear scar at each point is presented alongside the ECoF results in Figure 6. It should be noted that for the two graphs showing development of the $\mathrm{ECOF}$, the horizontal scales are different, and that the duration of the test for the DFL-CuNiln-Ti6Al4V contact architecture is more than four times longer than that for the DFL-Ti6Al4V contact architecture. Moreover, the working system lifetimes (defined as being the end of Stage II) are in a similar ratio (48 kilocycles and 237 kilocycles for the DFL-Ti6AI4V and the DFLCuNiln-Ti6AI4V contact architectures respectively). The initial contact between the DFLs on the two specimens in the pair results in values of ECoF of just under 0.5 for both contact architecture types; in the DFL-Ti6AI4V contact architecture, this is followed by a rapid decrease in the ECoF in the period just after 20 kilocycles. The start of this steep drop is identified with the point where the DFL has been removed to a depth where the underlying substrate begins to feature in the contact, and the rapid fall in ECoF is related to the rapid increase in the width of the contact over which the DFL has been removed (and thus the substrate is featuring). The behaviour with the DFL-CuNiln-Ti6Al4V contact architecture is somewhat different. The development of the ECOF is initially very similar (this is the region where the DFL behaviour is essentially independent of any underlying materials, and thus this similarity is to be expected). A similar drop in the ECoF is observed; however, the rate at which it falls is much slower, with the minimum coefficient of friction only being reached after around 80 kilocycles. The depth profile across the wear scar (Figure 6dFigure 6d) indicates that after 100 kilocycles, the penetration is only $40 \mu \mathrm{m}$, which is less than the full thickness of the DFL. The ECoF then rose slowly after 100 kilocycles, and showed signs of instability after about 220 kilocycles. After 327 kilocycles, the depth profile (Figure $6 \mathrm{~d}$ Figure $6 \mathrm{~d}$ ) indicates that the DFL has been fully penetrated. Examination of the fretting loops indicates that the Stage I contact stiffness (which is associated with a complex combination of the compliance of the contact and the rig fixturing) was around $65 \mathrm{MN} \mathrm{m}^{-1}$ ( $17 \mathrm{kcycles}$ ) and $50 \mathrm{MN} \mathrm{m}^{-1}$ (32 kcycles) for the DFL-Ti6AI4V and the DFL-CuNiln-Ti6AI4V contact architectures respectively.

To accompany the profilometry, Figure 7-Figure 7 (Stage I), Figure 8-Figure 8 (Stage II) and Figure 9 Figure 9 (Stage III) show low magnification cross-sections of the wear scars following the tests indicated in Figure 6Figure 6; unusually, these micrographs are presented in a form where the vertical magnification is ten times that of the horizontal magnification since this provides a clearer 
presentation of the damage incurred. In Figure 7Figure 7, it can be seen that in Stage I (after 5 kilocycles with the DFL-Ti6AI4V contact architecture), the DFL layer is intact; the corresponding image with the MoS2-CuNiln-Ti6Al4V contact architecture was very similar. It can be seen that after 5 kilocycles (Figure 7bFigure 7b), the outer surface of the DFL has been modified, but that these changes are quite subtle and only affect a layer about $2 \mu \mathrm{m}$ in thickness. The EDX results from the bulk and surface regions of the DFL (Figure $7 \mathrm{~b}$ Figure $7 \mathrm{~b}$ ) indicate very little change in chemistry at the surface, and that there is no evidence of any elements associated with the substrate at the wearing surface by this stage.

As outlined previously [22], Figure \&-Figure 8 (a) and (b) confirm the removal of the bulk of the DFL to the substrate interface in Stage II for the DFL-Ti6Al4V contact architecture (after 36 kilocycles). Towards the edges of the wear scar (where the DFL has been largely removed), it is clear that there has been no disruption of the initial surface roughness of the Ti6Al4V substrate into which the DFL is keyed. There is evidence of some remnants of the DFL remaining on the surface (Figure 8bFigure 8b), but it can be seen that this layer exhibits a generally homogeneous brightness (in contrast to the crosssection shown in Figure $7 \mathrm{~b}$-Figure $7 \mathrm{~b}$ where the binder and $\mathrm{MoS}_{2}$ in the DFL can be clearly distinguished from each other due to differences in brightness in BSE imaging). EDX analysis shows that this surface is chemically not very different from the original DFL; however, there is some evidence of titanium in the surface material (Figure 8-Figure 8 (b)). In contrast, for the DFL-CuNiln-Ti6Al4V contact architecture in Stage II, Figure \&-Figure 8 (c) and (d) indicate that after 100 kilocycles, the DFL has been removed to a thickness whereby the CuNiln underlayer is only in contact with the counterbody at a few selected points (i.e. the majority of the contact surface area is still made up of DFL); also, it can be seen that despite the removal of the DFL, the surface profile of the CuNiln is the same both inside and outside the wear scar, indicating that there has been no plastic deformation of the CuNiln associated with the fretting removal of the DFL. EDX analysis from the higher magnification image (Figure \&-Figure 8 (d)) indicates that the worn DFL surface shows no evidence of any material from either the CuNiln or the substrate at this stage.

The extent of damage in the two coating architectures at the end of Stage III is indicated in Figure 9Figure 9. In accord with the depth profile (Figure 6Figure 6), it is clear that for the DFL-Ti6AI4V contact architecture, material removal from the substrate has occurred to significant depths across the majority of the wear scar (Figure 9-Figure 9 (a)). The higher magnification image indicates that no traces of the DFL exist, a fact which is confirmed by the results of the EDX analysis presented alongside (Figure 9-Figure 9 (b) and supported by the large-area plan view EDX data of the same surface presented in Table 2). In contrast, for the DFL-CuNiln-Ti6AI4V contact architecture (Figure 9-Figure 9 (c)), it can be seen that the CuNiln layer is still intact, and although it has been penetrated to a significant depth across its whole surface, there is no exposure of the underlying substrate at this stage; the original rough surface of the CuNiln into which the DFL was keyed has been completely removed. However, the higher magnification image (Figure 9 -Figure 9 (d)) indicates that a thin surface layer exists in this region which has evidence of titanium (from the substrate of the counter body which did not have the CuNiln layer applied) and no molybdenum present, indicating complete removal of the DFL material, supported by the large-area plan view EDX data of the same surface presented in Table 2, where titanium and copper are the primary elements detected.

Figure 10-Figure 10 shows plan view images of the wear scars following the tests interrupted in Stage II (36 kilocycles and 100 kilocycles for the DFL-Ti6AI4V and the DFL-CuNiln-Ti6Al4V contact architectures respectively); large-area EDX analyses of the same wear scars are presented in Table 2. In addition, Figure 11-Figure 11 provides elemental line profiles across the same wear scars generated via the more surface-sensitive XPS analysis technique. For the DFL-Ti6Al4V interrupted in Stage II (Figure 10-Figure 10 (a)), it can be seen that that the surface is made up of different regions; those 
with a lower brightness still have evidence of DFL being present, whereas those with a higher brightness are regions where the DFL has been removed, leaving the substrate exposed. Ploughing marks can be seen running across the surface, but the surface is generally quite smooth indicating that wear has been mild at this point. EDX analysis indicates that the surface is still dominated by the DFL, but there is also evidence of the titanium alloy substrate as part of the surface material (the measured titanium content via EDX analysis is $\approx 9$ wt\%, equivalent to $\approx 4.5$ at\%). However, the XPS data (Figure 11 Figure 11 (a)) show a much lower titanium content across the surface ( $\approx 1$ at $\%$ ), which indicates that the surface material which appears titanium-rich via BSE imaging and EDX analysis is in fact covered by a layer which is rich in carbon, oxygen, molybdenum and sulfur, but that this layer is thin enough that it is only detected by XPS analysis but not by EDX analysis and BSE imaging. Moreover, the XPS trace across the wear scar indicates a substantial reduction in carbon in the wear scar with an increase in molybdenum and sulfur, indicating that the surface of the wear scar is preferentially enriched in $\mathrm{MoS}_{2}$ by the wear process itself at the expense of the epoxy binder.

For the DFL-CuNiln-Ti6AI4V contact architecture interrupted in Stage II (Figure 10-Figure 10 (b)), it can be seen that the surface is broadly covered with the darker contrast DFL, with only very small patches of the higher contrast CuNiln being visible. This is supported by the large-area EDX analysis (Table 2) which indicates a copper content of only $3 \mathrm{wt} \%$. The DFL surface is rough, and indicates that material is being removed by delamination. The XPS trace across the wear scar (Figure 11-Figure 11 (b)) indicates that no titanium (substrate) or copper (CuNiln layer) can be detected at this stage (this is in contrast to the data in Figure 11-Figure 11 (a) where a small amount of titanium could be detected). However, a substantial reduction in carbon in the wear scar is seen again, along with an increase in molybdenum and sulfur, indicating that the surface of the wear scar is preferentially enriched in $\mathrm{MoS}_{2}$ by the wear process itself

\section{Discussion}

Previous work [22] has shown that for the DFL-Ti6Al4V contact architecture, Stage I ends when the DFL has been penetrated to the substrate interface, but that during Stage II, a low friction surface material is formed and exists until it too is degraded / removed, whereupon the coefficient of friction begins to become unstable due to true substrate-substrate contact. The lifetime of Stage II is a significant portion of the overall lifetime of the system, and the duration of this stage is inversely proportional to the contact pressure. The metal - DFL surface formed in stage II has a high durability; it is of limited thickness, and yet the duration of Stage II (31 kilocycles) is longer than that of Stage I (20 kilocycles).

The role of the CuNiln in the lifetime of such systems has been discussed in previous work; it has been suggested that the low hardness and stiffness of the CuNiln may result in deformation (both elastic and plastic) which reduce the severity of the contact and thus extend the lifetime $[18,19]$. Others have ascribed the benefits of the CuNiln in these systems to its high roughness which promotes retention of the DLF layer [17]. In the current work (where systems with and without the CuNiln layer are directly compared), it is observed that the addition of a plasma-sprayed CuNiln layer before addition of the DLF significantly extends the lifetime of the system. It is argued that Stage I (where the DFL is removed until the underlying metal begins to be exposed) is of approximately the same duration for both the DFL-Ti6AI4V and the DFL-CuNiln-Ti6Al4V contact architectures, and that differences in system lifetimes are primarily associated with the evolution of the ECoF in Stage II. No evidence of plastic deformation of the CuNiln below the contact is observed when the DFL layer is still largely intact, even when the CuNiln is very close to the wearing surface (see Figure 8Figure \& (c)). Also, despite differences in the contact stiffness for the two coating architectures, the elastic displacement in both cases is a 
very small fraction of the overall displacement amplitude (i.e. in both cases, the displacement amplitude of $300 \mu \mathrm{m}$ is still dominated by contact slip).

Instead, it is proposed (in line with the observations of Fridrici at el. [17]) that it is primarily the surface roughness of the CuNiln underlayer which results in the significant lifetime extension in this system. The work on the DFL-Ti6AI4V coating architecture shows that Stage II (where the wearing surface consists of both metal and DFL) provides a low coefficient of friction and exhibits high durability (i.e. high resistance to wear). The high surface roughness of the metal - DFL interface in the DFL-CuNilnTi6Al4V system means that the fraction of metal in the wearing contact increases more gradually with depth of wear as it passes through this rough interface; the number of cycles over which this transition occurs will be further extended by the fact that the surfaces that consist of both metal and DFL exhibit very low rates of wear, and so are penetrated more slowly. This is illustrated schematically in Figure 12 Figure 1312; in the case of a low roughness interface between the DFL and the underlying metal (representing the DFL-Ti6AI4V coating architecture - Figure 12-Figure 1312 (a)), then it can be seen that that rate of change of the nature of the interface (in terms of fractions of metal and DFL) with depth of wear is high; this results in the rapid reduction in ECoF following initial DFL penetration (just after 20 kilocycles) with this coating architecture (see Figure 6-Figure 6 (a)). In contrast, in the case of a high roughness interface between the DFL and the underlying metal (representing the DFL-CuNiINTi6Al4V coating architecture - Figure 12 Figure 1312 (b)), then it can be seen that the rate of change of the nature of the interface (in terms of fractions of metal and DFL) with depth of wear is much lower; this results in the much more gradual reduction in ECoF following initial DFL penetration with this coating architecture (see Figure 6 -Figure 6 (b)).

Also, given that it has been argued that the mixed metal-DFL interfaces exhibit high durability (i.e. low rates of wear), then the extended number of cycles until the onset of Stage III (where metal-metal contact with no influence of the DFL first dominates) with the higher roughness interface can also be rationalised. It is recognised that an assumption in this discussion is that the DFL-metal material always exhibits properties of low friction and high durability; there will clearly be both physical and chemical interactions between the metal and DFL, and it is therefore noted that the characteristics of this metalDFL surface will depend upon the metal type, the DFL type and upon the complex interactions between them.

In light of the hypotheses presented here and in previous work [22], it is clear that the wear of the DFL alone is generally quite rapid (and makes up a small fraction of the total system lifetime), but that the wear of the mixed DFL-metallic surface material is much less rapid (and thus makes up a large fraction of the total system lifetime). In technological terms, this indicates that the system lifetime will be very sensitive to the profile (roughness) of the metal - DFL interface, but much less sensitive to variations in the precise thickness of the DFL. As such, in terms of extending lifetime of such systems, a DFLmetal interface with high roughness is desirable; to reduce variability in system lifetime, the variations in the roughness of the metal onto which the DFL is to be sprayed needs to be controlled.

\section{Conclusions}

The behaviour of an epoxy-bonded DFL sprayed directly onto a grit-blasted titanium alloy has been compared with that of the same DFL sprayed onto a CUNiln interlayer which itself had been plasma sprayed onto the titanium alloy. The behaviour was examined in terms of coefficient of friction and system lifetime (durability) under fretting. The lifetimes of the systems have been understood in terms of a coherent phenomenological model which sub-divides the evolution of the behaviour into two stages (a third stage was identified, but failure of the system was linked with entry into this stage). In 
both system architectures, the first regime involves wear of the DFL; the influence of the metal onto which the DFL had been deposited was small, and thus the behaviour in this stage was very similar for both systems. The behaviour in the second stage is controlled by the characteristics of the material at the interface which is made up of both metal and DFL. This material exhibits characteristics of low friction and high wear resistance. The changes in the makeup of the interface are very sensitive to the profile (roughness) of the interface between the metal and the DFL. Higher roughness results in reduced rates of change in behaviour and a significant extension of the duration over which the surface material is made up of a mixture of DFL and metal; accordingly, the high durability of the system with the CuNiln underlayer is primarily ascribed to the high roughness of the underlayer in its as-sprayed form onto which the DFL was deposited.

\section{Acknowledgments}

Rolls-Royce plc are gratefully acknowledged for their funding of this research.

\section{References}

1. Hills, D.A., Mechanics of fretting fatigue. Wear, 1994. 175(1-2): p. 107-113.

2. V. Fridrici, S. Fouvry, and P. Kapsa, Fretting wear behaviour of a Cu-Ni-In plasma coating. Surface \& Coatings Technology, 2003. 163-164: p. 429-434.

3. Golden, P.J. and T. Nicholas, The effect of angle on dovetail fretting experiments in Ti$6 A l-4 V$. Fatigue \& Fracture of Engineering Materials \& Structures, 2005. 28(12): p. 1169-1175.

4. Rajasekaran, R. and D. Nowell, Fretting fatigue in dovetail blade roots: Experiment and analysis. Tribology International, 2006. 39(10): p. 1277-1285.

5. Li, Z.Y., X.L. Liu, G.Q. Wu, and W. Sha, Observation of fretting fatigue cracks of Ti6A14V titanium alloy. Materials Science and Engineering a-Structural Materials Properties Microstructure and Processing, 2017. 707: p. 51-57.

6. Prevey, P.S., N. Jayaraman, R.A. Ravindranath, and M. Shepard, Mitigation of Fretting Fatigue Damage in Blade and Disk Pressure Faces With Low Plasticity Burnishing. Journal of Engineering for Gas Turbines and Power-Transactions of the Asme, 2010. 132(8).

7. Liu, C.S., D.X. Liu, X.H. Zhang, S.M. Yu, and W.D. Zhao, Effect of the Ultrasonic Surface Rolling Process on the Fretting Fatigue Behavior of Ti-6Al-4V Alloy. Materials, 2017. 10(7).

8. Tang, C.B., D.X. Liu, B. Tang, X.H. Zhang, L. Qin, and C.S. Liu, Influence of plasma molybdenizing and shot-peening on fretting damage behavior of titanium alloy. Applied Surface Science, 2016. 390: p. 946-958.

9. Liu, Z.G., T.I. Wong, W. Huang, N. Sridhar, and S.J. Wang, Effect of Surface Polishing Treatment on the Fatigue Performance of Shot-Peened Ti-6Al-4V Alloy. Acta Metallurgica Sinica-English Letters, 2017. 30(7): p. 630-640.

10. Li, K., X.S. Fu, R.D. Li, P.T. Gai, Z.Q. Li, W.L. Zhou, and G.Q. Chen, Fretting fatigue characteristic of Ti-6Al-4V strengthened by wet peening. International Journal of Fatigue, 2016. 85: p. 65-69.

11. Kumar, S., K. Chattopadhyay, and V. Singh, Effect of ultrasonic shot peening on LCF behavior of the Ti-6Al-4V alloy. Journal of Alloys and Compounds, 2017. 724: p. 187197. 
12. Kim, K. and A.M. Korsunsky, Dissipated energy and fretting damage in CoCrAlY$\mathrm{MoS}_{2}$ coatings. Tribology International, 2010. 43(3): p. 676-684.

13. Korsunsky, A.M., A.R. Torosyan, and K. Kim, Development and characterization of low friction coatings for protection against fretting wear in aerospace components. Thin Solid Films, 2008. 516(16): p. 5690-5699.

14. Korsunsky, A.M. and K. Kim, Dissipated energy and friction coefficient evolution during fretting wear of solid lubricant coatings. Tribology International, 2010. 43(56): p. 861-867.

15. Mary, C., S. Fouvry, J.M. Martin, and B. Bonnet, Pressure and temperature effects on fretting wear damage of a $\mathrm{Cu}$-Ni-In plasma coating versus Ti17 titanium alloy contact. Wear, 2011. 272: p. 18-37.

16. Kim, K. and A.M. Korsunsky, Effects of imposed displacement and initial coating thickness on fretting behaviour of a thermally sprayed coating. Wear, 2011. 271(7-8): p. 1080-1085.

17. Fridrici, V., S. Fouvry, P. Kapsa, and P. Perruchaut, Impact of contact size and geometry on the lifetime of a solid lubricant. Wear, 2003. 255(7-12): p. 875-882.

18. Sabeya, G.R.Y.N., J.Y. Paris, and J. Denape, Fretting wear of a coated titanium alloy under free displacement. Wear, 2008. 264(3-4): p. 166-176.

19. Fouvry, S., V. Fridrici, C. Langlade, P. Kapsa, and L. Vincent, Palliatives in fretting: A dynamical approach. Tribology International, 2006. 39(10): p. 1005-1015.

20. Hager Jr, C.H., J.H. Sanders, and S. Sharma, Unlubricated gross slip fretting wear of metallic plasma-sprayed coatings for Ti6Al4V surfaces. Wear, 2008. 265(3-4): p. 439451.

21. Hager Jr, C.H., J. Sanders, S. Sharma, and A. Voevodin, Gross slip fretting wear of CrCN, TiAlN, Ni, and CuNiIn coatings on Ti6Al4V interfaces. Wear, 2007. 263(1-6 SPEC. ISS.): p. 430-443.

22. K. Barman, P.H. Shipway, K.T. Voisey, and G. Pattinson, Evolution of damage in $M o S_{2}$-based dry film lubricants (DFLs) in fretting wear - The effect of DFL thickness and contact geometry. Progress in Organic Coatings, 2017. 105: p. 67-80.

23. Fouvry, S., P. Duó, and P. Perruchaut, A quantitative approach of Ti-6Al-4V fretting damage: friction, wear and crack nucleation. Wear, 2004. 257(9-10): p. 916-929.

24. Barman, K., P.H. Shipway, K.T. Voisey, and G. Pattinson, Evolution of damage in $\mathrm{MoS}_{2}$-based dry film lubricants (DFLs) in fretting wear - the effect of DFL thickness and contact geometry. Surface and Coatings Technology, 2017. 105: p. 67-80.

25. Mulvihill, D.M., M.E. Kartal, A.V. Olver, D. Nowell, and D.A. Hills, Investigation of non-Coulomb friction behaviour in reciprocating sliding. Wear, 2011. 271(5-6): p. 802816. 


\section{Tables}

Table 1: Fretting test conditions

\begin{tabular}{ll}
\hline Normal Load $(\mathrm{N})$ & 575 \\
Frequency $(\mathrm{Hz})$ & 2.5 \\
Displacement amplitude $(\mu \mathrm{m})$ & 300 \\
Room temperature $\left({ }^{\circ} \mathrm{C}\right)$ & $20 \pm 3$ (ambient) \\
Relative humidity $(\%)$ & $30 \pm 5$ (ambient) \\
\hline
\end{tabular}

Table 2 Analysis from surface of wear scars for tests interrupted at various points. EDX analysis of titanium, molybdenum and copper representing the substrate, DFL and CuNiln materials respectively (elements included in the EDX ZAF analysis: $\mathrm{Ti}, \mathrm{Al}, \mathrm{V}, \mathrm{Mo}, \mathrm{S}, \mathrm{C}, \mathrm{O}$ in the case of the DFL-Ti6Al4V contact architecture, and $\mathrm{Ti}, \mathrm{Al}, \mathrm{V}, \mathrm{Mo}, \mathrm{S}, \mathrm{C}, \mathrm{O}, \mathrm{Cu}, \mathrm{Ni}$, In in the case of the DFL-Ti6AI4V DFL-CuNiln-Ti6AI4V contact architecture). The maximum depth of wear scar in each case is also presented.

\begin{tabular}{|l|l|l|l|l|l|l|}
\hline Architecture & $\begin{array}{l}\mathbf{N} \\
\text { kilocycles }\end{array}$ & Stage & $\begin{array}{l}\text { Ti } \\
\text { wt\% }\end{array}$ & $\begin{array}{l}\text { Mo } \\
\text { wt\% }\end{array}$ & $\begin{array}{l}\text { Cu / } \\
\text { wt\% }\end{array}$ & Depth of scar / $\boldsymbol{\mu m}$ \\
\hline DFL-Ti6Al4V & 36 & Stage II & 9 & 28 & - & 64 \\
\hline DFL-Ti6AI4V & 68 & Stage III & 49 & 0 & - & 122 \\
\hline & & & & & & \\
\hline DFL-CuNiln-Ti6AI4V & 100 & Stage II & 0 & 30 & 3 & 42 \\
\hline DFL-CuNiln-Ti6AI4V & 327 & Stage III & 13 & 1 & 29 & 63 \\
\hline
\end{tabular}

\section{Figure Captions}

Figure 1 Development of ECoF for the DFL-Ti6AI4V system, along with generic categorisation of the three different stages in behaviour as previously outlined [22].

Figure 2 Schematic diagram of a fretting loop showing and increase in tractional force $Q$ as slip proceeds (after [25]).

Figure $2-3$ Schematic diagram illustrating the details of the profilometry procedures for the flat fretting specimens.

Formatted: Norma

Figure 3-4 SE-SEM images of the surfaces prior to DFL application; (a) grit-blasted Ti6Al4V; (b) plasma-sprayed CuNiln

Figure 45 Surface profile of the two surface types prior to application of the DFL

Figure 65: Low magnification (left) and high magnification (right) SEM micrograph of the surface of the as-cured DFL paint coating $\mathrm{MoS}_{2}$

Figure 6-7 Evolution of ECoF with number of cycles for both completed and interrupted tests (indicating the number of cycles at interruption or completion), along with average depth profiles across the corresponding wear scars; (a), (b) DFLTi6Al4V system; (c), (d) DFL-CuNiln-Ti6Al4V system.

Figure 78 BSE micrographs of a wear scar cross-section for DFL-Ti6AI4V in stage I (after 5 k cycles). (a) low magnification image with a distorted aspect ratio (vertical magnification being ten times the horizontal magnification); (b) high magnification image of representative sections along with EDX data (elements included in the ZAF analysis: Ti, Al, V, Mo, $S, C, O)$ representing the titanium and molybdenum contents of the areas indicated. 
Figure 8-9 BSE of wear scar cross-sections for both DFL-Ti6AI4V and DFL-CuNiln-Ti6Al4V in Stage II corresponding to the tests described in Figure 6Figure 9. (a) and (c) are a low magnification images with a distorted aspect ratio (vertical magnification being ten times the horizontal magnification); (b) and (d) are high magnification images of representative sections of the corresponding scar surface along with EDX data (elements included in the ZAF analysis: Ti, Al, V, Mo, S, C, $\mathrm{O}, \mathrm{Cu}, \mathrm{Ni}, \mathrm{In}$ ) representing the titanium and molybdenum contents of the areas indicated. (a) and (b) MoS2-Ti6Al4V; following 36 kilocycles (c) and (d) DFL-CuNiln-Ti6AI4V following 100 kilocycles.

Figure $9-10$ BSE of wear scar cross-sections for both DFL-Ti6AI4V and DFL-CuNiln-Ti6AI4V in Stage III corresponding to the tests described in Figure 6Figure 9. (a) and (c) are a low magnification images with a distorted aspect ratio (vertical magnification being ten times the horizontal magnification); (b) and (d) are high magnification images of representative sections of the corresponding scar surface along with EDX data (elements included in the ZAF analysis: Ti, Al, V, Mo, S, C, $\mathrm{O}, \mathrm{Cu}, \mathrm{Ni}, \mathrm{In}$ ) representing the titanium, copper and molybdenum contents of the areas indicated. (a) and (b) DFL-Ti6Al4V following 68 kilocycles (c) and (d) DFL-CuNiln-Ti6Al4V following 327 kilocycles.

Figure 10-11 BSE plan view micrographs of wear scars for both the DFL-Ti6Al4V and the DFL-CuNiln-Ti6AI4V systems following interruption in Stage II at both low (left) and high (right) magnification (the high magnification image is of the region shown in the white box in the low magnification image); (a) DFL-Ti6Al4V following 36 kilocycles; (b) DFL-CuNilnTi6Al4V following 100 kilocycles.

Figure 1112 XPS analysis across the wear scars for both the DFL-Ti6Al4V and the DFL-CuNiln-Ti6Al4V systems following interruption in Stage II showing the atomic percentage of elements across the wear scar.; (a) DFL-Ti6Al4V following 36 kilocycles (positionally, $0 \mathrm{~mm}$ and $6 \mathrm{~mm}$ are outside the scar, with the scar existing between these lateral positions); (b) DFL-CuNiln-Ti6Al4V following 100 kilocycles (positionally, $\mathbf{0 ~ m m}$ and $8 \mathrm{~mm}$ are outside the scar, with the scar existing between these lateral positions).

Figure 1312 Schematic diagram of penetration of cylindrical body through an interface of different roughnesses, with penetration increasing from left to right; (a) low roughness interface; (b) high roughness interface. The differences in penetration depth are indicated in the right hand side of each part. 